\title{
An improved method for dynamic modelling of a slab track on a high-speed railway
}

\author{
H. Shi, Z. Yu \& H. Shi \\ School of Mechanical, Electrical Control Engineering, \\ Beijing JiaoTong University, China
}

\begin{abstract}
Cement emulsified asphalt mortar (CA mortar) deterioration will accelerate the structural damage of a track and even have adverse effects on traffic safety if serious enough. In the traditional ballastless track dynamic equation, CA mortar is simplified as spring and damping are continuously distributed along the track plate which cannot simulate the influences of CA mortar deterioration with an arbitrary length on the dynamic characteristics of a track. An improved method was proposed to establish a vehicle-ballastless track-subgrade coupled system vertical improved model based on Matlab. CA mortar was discretized by taking the distance in which one vehicle travels in a simulation step as a unit. Each unit was simplified as spring and a damping concentrated on one point that transferred the distribution force of CA mortar to track a plate in vibration differential equation to concentrated force. The proposed model was compared with the traditional Zhai-Sun's model and the effect of CA mortar deterioration on vibration responses of the slab track was studied. The results show that the vibration responses of vehicle and track in the proposed model have basically concurred with the classical model, and it is effective. Compared to the normal condition, the rail and track plate displacement obviously increase during the action of CA mortar deterioration. The analyses of influences of CA mortar deterioration on dynamic properties of ballastless track have great application potentiality for further detection of CA mortar deterioration.
\end{abstract}

Keywords: ballastless track, CA mortar deterioration, vibration responses, discretization. 


\section{Introduction}

With the rapid development of high-speed railways, a ballastless track with its advantages of better stiffness uniformity, higher running stability, and lower maintenance cost has been widely used in various countries [1]. The CRTSII slab ballastless track on the subgrade consists of rail, fastening system, track slab, cement emulsified asphalt mortar (CA mortar) layer, and a concrete supporting layer. As one of the main damage forms of slab track, the deterioration of a CA mortar layer will significantly contribute to the potential for failure of the slab tracks and even have adverse effects on traffic safety if serious enough. Therefore, to establish a vehicle-track coupling model that can simulate the influences of CA mortar deterioration with arbitrary length on the dynamic characteristics of track is quite desirable.

At present, most research on slab tracks has focused on structural design and static analysis, and few studies have concentrated on the dynamic analysis of slab tracks under moving vehicles. Auersch [2] calculated the dynamic interaction within the slab track system in detail using a combination of the finite element method and the boundary element method. Bezin et al. [3] developed a flexible track model and used multi-body dynamics software to simulate the dynamic interaction between a vehicle and two new kinds of slab track and compared their performance to conventional ballasted track. Zhai et al. [4] developed a vehicle/slab track interaction model based on the theory of vehicletrack coupling dynamics, investigated the dynamic properties of slab tracks and analyzed the effects of the elasticity and damping of the CA-layer under the slab on system dynamics. Cai and $\mathrm{Xu}$ [5] established the dynamic model of high-speed train-frame slab track based on the theory of elastic thin plate vibration and weighted residual method and analyzed the influence of elastic modulus of CA mortar on dynamic response of frame slab track. In influence aspects of the deterioration of CA mortar, Xiang et al. [7] studied the effect of voided slab induced by deteriorations of CA mortar layer according to the analysis theory of spatial vibration of high-speed train and slab track system. Wang et al. [8] analyzed the probable deterioration mechanisms and tried to find out their effects on CRTSII slab track structure by computer simulation analysis with finite element method. Zhu et al. [9] established the calculation model of CRTSII slab track on railway subgrade on the base of finite element theory by using the ANSYS software and studied the CRTSII slab track's stress state and deformation state.

For a long time, research on the influence of CA mortar deterioration both at home and abroad has been based on finite element modeling. In the traditional ballastless track dynamic equation, CA mortar is simplified as spring and damping continuously distributed along track plate which cannot simulate the influences of CA mortar deterioration with arbitrary length on the dynamic characteristics of track. An improved method was proposed to establish a vehicle-ballastless track-subgrade coupled system vertical improved model based on Matlab. CA mortar was discretized by taking the distance which one vehicle travels in a simulation step as a unit. Each unit was simplified as spring and a 
damping concentrated on one point that transferred the distribution force of CA mortar to track plate in vibration differential equation to concentrated force. Take CRH2 emu trailer and CRTS II slab track for example; the proposed model was compared with the traditional Zhai-Sun's model to verify its effectiveness and the effect of CA mortar deterioration on vibration responses of the slab track was studied. The analyses of influences of CA mortar deterioration on dynamic properties of ballastless track have great application potentiality for further detection of CA mortar deterioration.

\section{Vehicle-ballastless track-subgrade coupled system vertical improved model}

The vehicle-ballastless track-subgrade vertical coupling model is shown in fig. 1, which is composed of the vehicle model, track model, and wheel-rail interaction model. According to Zhai-Sun's model [10], the vehicle is considered as a multibody system running on the rail at the speed of $v$, consisting of the car body, the front and rear bogies, and the wheelsets. The track is modeled as the triplelayer beam which considered rail, slab, and concrete supporting layer. In this paper, the wheel/rail normal force was determined by Hertz nonlinear elastic contact theory.

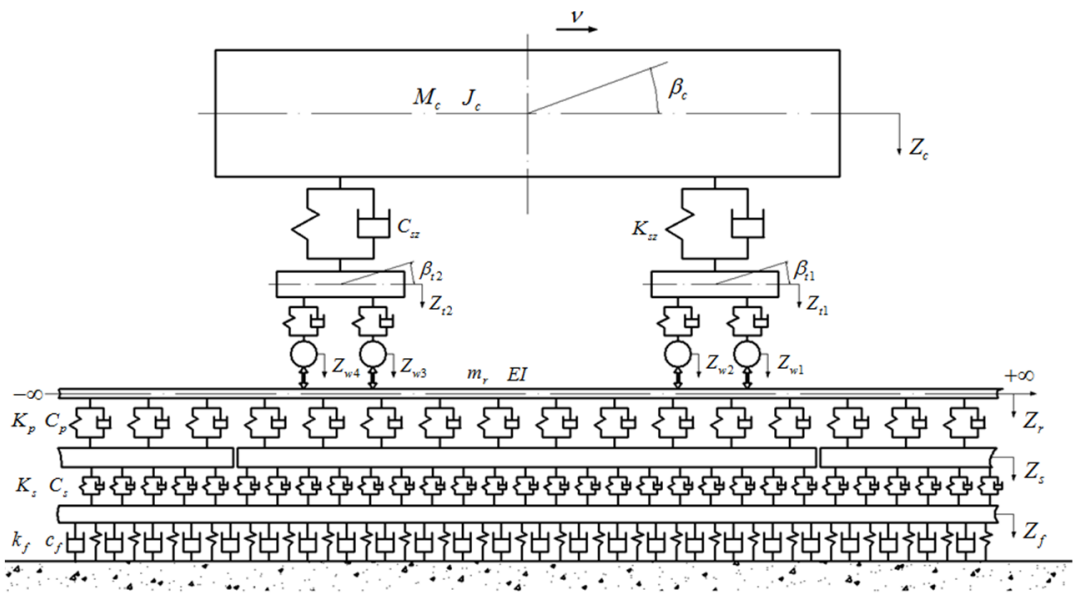

Figure 1: A vehicle-track-subgrade coupling system.

\subsection{Vehicle model}

Each vehicle is composed of one car body, two bogies, and four wheelsets, which are considered to be rigid bodies; four primary and two secondary suspension systems are represented by linear springs and dampers. Including the vertical displacement and nodding motion of the car and front and rear bogies, vertical vibration of the wheelsets, the total degrees of freedom are ten.

The general form of the equations of motion for the vehicle can be written as:

$$
\left[M_{V}\right]\left\{\ddot{Z}_{V}\right\}+\left[C_{V}\right]\left\{\dot{Z}_{V}\right\}+\left[K_{V}\right]\left\{Z_{V}\right\}=\left\{P_{V}\right\}
$$


where the subscript $v$ corresponds to the vehicle, $\left[M_{V}\right]$ is the mass matrix of the vehicle, $\left[C_{V}\right],\left[K_{V}\right]$ are the damping and the stiffness matrices, $\left\{Z_{V}\right\},\left\{\dot{Z}_{V}\right\},\left\{\ddot{Z}_{V}\right\}$ are the generalized displacements, velocities, and accelerations of the vehicle system, respectively. $\left\{P_{V}\right\}$ is the generalized load of the vehicle system.

The vehicle and the slab track are coupled by the interaction force between the rail and the wheel. According to the nonlinear Hertzian theory, the wheel-rail contact force is given by the equation

$$
p_{j}(t)= \begin{cases}\left\{\frac{1}{G}\left[Z_{w j}(t)-Z_{r}\left(x_{w j}, t\right)-Z_{0}(t)\right]\right\}^{3 / 2} & \left(Z_{w j}(t)-Z_{r}\left(x_{w j}, t\right)-Z_{0}(t)>0\right) \\ 0 & \left(Z_{w j}(t)-Z_{r}\left(x_{w j}, t\right)-Z_{0}(t)<0\right)\end{cases}
$$

where $Z_{w j}(t)$ is the vertical displacement of the $j$ th wheel at time $t, Z_{r}\left(x_{w j}, t\right)$ is the vertical rail displacement at the $j$ th wheel position, and $Z_{0}(t)$ is the irregularities at the wheel-rail interface. $G=3.86 R^{-0.115} \times 10^{-8} \mathrm{~m} / \mathrm{N}^{2 / 3}, \quad R$ is the wheel half of nominal diameter.

\subsection{Improved track model}

According to the literature [10], the equations of motion of the rail are given in form of the second-order vibration differential equation:

$$
\begin{aligned}
& \ddot{q}_{k}(t)+\sum_{i=1}^{N} C_{p i} Y_{k}\left(x_{i}\right) \sum_{h=1}^{N M} Y_{h}\left(x_{i}\right) \dot{q}_{h}(t)+\frac{E I}{m_{r}}\left(\frac{k \pi}{l}\right)^{4} q_{k}(t)+\sum_{i=1}^{N} K_{p i} Y_{k}\left(x_{i}\right) \sum_{h=1}^{N M} Y_{h}\left(x_{i}\right) q_{h}(t) \\
& -\sum_{i=1}^{N} C_{p i} Y_{k}\left(x_{i}\right) \dot{Z}_{s i}(t)-\sum_{i=1}^{N} K_{p i} Y_{k}\left(x_{i}\right) Z_{s i}(t)=\sum_{j=1}^{4} p_{j}(t) Y_{k}\left(x_{w j}\right) \quad(k=1 \sim N M)
\end{aligned}
$$

where $q_{k}(t)$ is modal coordinates of the rail, $K_{p i}$ and $C_{p i}$ respectively stand for the stiffness and damping of the pad that each fastener corresponds under the rail. $Z_{s i}(t)$ is the displacement of track plate that each fastener corresponds to. $p_{j}(t)$ is the interaction force between the wheel and contacted rail. $N M$ is the modal order of the rail.

In the vehicle-track coupling model, the stiffness and damping coefficient of spring-damper unit in corresponding position may be set to 0 to simulate the deterioration of the CA mortar, and the range of deterioration can be reflected by setting different length. In the traditional ballastless track dynamic equation, CA mortar is simplified as spring and damping continuously distributed along track plate and its force to track plate in dynamics equation is in the form of a distributed force. Therefore, Only by changing the stiffness and damping values of the CA mortar under the entire track plate to simulate the deterioration of the CA mortar layer with a piece of track plate length, and can't simulate arbitrary length. In this paper, the CA mortar was discretized to transfer the distribution force of $\mathrm{CA}$ mortar to track plate in vibration differential equation to concentrated force and a vehicle-ballastless track-subgrade coupled system vertical improved model was established. 
CA mortar was discretized by taking the distance $\Delta l=v \Delta t$ in which one vehicle travels with the speed of $v$ in a simulation step $\Delta t$ as a unit. Each unit was simplified as spring and a damping concentrated on one point. Therefore, there are $L_{s} / \Delta l$ units and the concentrated spring and damping of each unit is $k_{s p}=k_{s} \Delta l, c_{s p}=c_{s} \Delta l$ respectively.

As shown in fig. 2, the differential equation of track plate with discretized CA mortar is:

$$
E_{s} I_{s} \frac{\partial^{4} Z_{s}(x, t)}{\partial x^{4}}+\frac{M_{s}}{L_{s}} \frac{\partial^{2} Z_{s}(x, t)}{\partial t^{2}}=\sum_{i=1}^{n_{0}} F_{r s i}(t) \delta\left(x-x_{i}\right)-\sum_{p=1}^{m_{0}} F_{s f p}(t) \delta\left(x-x_{p}\right)
$$

where the subscript $s$ corresponds to the track plate, the subscript $f$ corresponds to the concrete support layer. $Z_{s}(x, t)$ and $Z_{f}(x, t)$ stand for the vertical displacement, $M_{s}$ and $L_{s}$ is the mass and length of a track plate, $n_{0}$ is the number of fastener on a track plate, $m_{0}$ is the number of discretized units of a track plate. $F_{r s i}(t)$ and $F_{s f p}(t)$ stands for the reaction force of the spring-damping element, which can be defined as:

$$
\begin{gathered}
F_{r s i}(t)=K_{p i}\left[Z_{r}\left(x_{i}, t\right)-Z_{s}\left(x_{i}, t\right)\right]+C_{p i}\left[\dot{Z}_{r}\left(x_{i}, t\right)-\dot{Z}_{s}\left(x_{i}, t\right)\right] \\
F_{s p p}(t)=K_{s p}\left[Z_{s}\left(x_{p}, t\right)-Z_{f}\left(x_{p}, t\right)\right]+C_{s p}\left[\dot{Z}_{s}\left(x_{p}, t\right)-\dot{Z}_{f}\left(x_{p}, t\right)\right]
\end{gathered}
$$

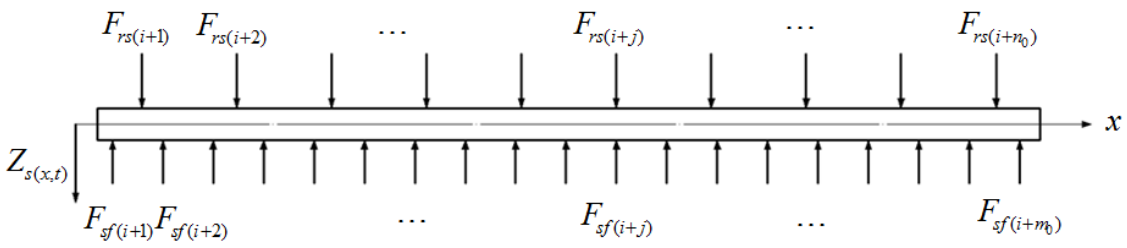

Figure 2: The vibration analysis model of a track plate.

With the segregation variable method, the displacements of track plate are considered as a linear combination of modal coordinates and mode shape functions, which are expressed as follows:

$$
Z_{s}(x, t)=\sum_{n=1}^{N M S} X_{n}(x) T_{n}(t)
$$

where the subscript $n$ means the order of the rail mode and $T_{n}(t)$ is the nth order modal coordinate.

Substituting eqn (7) in eqn (4), the mode equations can be written as:

$$
E_{s} I_{s} \sum_{n=1}^{N M S} \frac{\partial^{4} X_{n}(x)}{\partial x^{4}} T_{n}(t)+\frac{M_{s}}{L_{s}} \sum_{n=1}^{N M S} X_{n}(x) \ddot{T}_{n}(t)=\sum_{i=1}^{n_{0}} F_{r s i}(t) \delta\left(x-x_{i}\right)-\sum_{p=1}^{m_{0}} F_{s p p}(t) \delta\left(x-x_{p}\right)
$$


In order to investigate the orthogonality of the modes, both sides of eqn (8) are multiplied by $X_{p}(x)(p=1 \sim N M S)$, and then are integrated with respect to $x$ in the calculated length of the track plate.

$$
\begin{aligned}
& \sum_{n=1}^{N M S} T_{n}(t) \int_{0}^{L_{s}} X_{p}(x) \frac{\partial^{4} X_{n}(x)}{\partial x^{4}} d x+\frac{M_{s}}{E_{s} I_{s} L_{s}} \sum_{n=1}^{N M S} \ddot{T}_{n}(t) \int_{0}^{L_{s}} X_{p}(x) X_{n}(x) d x \\
& =\frac{1}{E_{s} I_{s}} \sum_{i=1}^{n_{0}} F_{r s i}(t) \int_{0}^{L_{s}} X_{p}(x) \delta\left(x-x_{i}\right) d x-\frac{1}{E_{s} I_{s}} \sum_{p=1}^{m_{0}} F_{s f p}(t) \int_{0}^{L_{s}} X_{p}(x) \delta\left(x-x_{p}\right) d x
\end{aligned}
$$

According to the equilibrium constraints of eqn (9), when the subscript $r$ is unequal to subscript $s$, the obligatory relations of different mode function can be obtained as:

$$
\left\{\begin{array}{c}
\int_{0}^{L_{s}} X_{r}(x) X_{s}(x) d x=0 \\
\int_{0}^{L_{s}} X_{r}(x) \frac{d^{4} X_{s}(x)}{d x^{4}} d x=0
\end{array} \quad(r \neq s)\right.
$$

Then

$$
\begin{aligned}
& \frac{M_{s}}{L_{s}} \ddot{T}_{n}(t) \int_{0}^{L_{s}} X_{n}^{2}(x) d x+E_{s} I_{s} T_{n}(t) \int_{0}^{L_{s}} X_{n}(x) \frac{d^{4} X_{n}(x)}{d x^{4}} d x \\
& +\sum_{q=1}^{m_{0}} F_{s f q}(t) X_{n}\left(x_{q}\right)=\sum_{i=1}^{n_{0}} F_{r s i}(t) X_{n}\left(x_{i}\right)
\end{aligned}
$$

When the subscript $r$ is equal to subscript $s$, the normalisation equation of mode can be defined as:

$$
\int_{0}^{L_{s}} X_{n}^{2}(x) d x=L_{s}
$$

Consequently, the respective mode function must satisfy the following equation:

$$
\int_{0}^{L_{s}} X_{n}(x) \frac{d^{4} X_{n}(x)}{d x^{4}} d x=L_{s} B
$$

where $B$ is equal to $\omega_{s}^{2} M_{s} /\left(E_{s} I_{s} L_{s}\right)$ and $\omega_{s}$ represents the natural frequency of track plate.

With the resultant eqn (12) substituted in eqn (11), the expressions of motion equation described by the generalised modal displacement are then

$$
\ddot{T}_{n}(t)+\frac{E_{s} I_{s} B}{M_{s}} \cdot L_{s} \cdot T_{n}(t)+\sum_{p=1}^{m_{0}} \frac{F_{s f p}(t)}{M_{s}} X_{n}\left(x_{p}\right)=\sum_{i=1}^{n_{0}} \frac{F_{r s i}(t)}{M_{s}} X_{n}\left(x_{i}\right)
$$

Likewise, the expression of motion equation of the concrete support layer which is modelled as infinite-length Euler beams supported in the continuous distribution of linear spring and damping described by the generalised modal displacement is:

$$
\ddot{q}_{m}(t)+\frac{c_{f}}{m_{f}} \dot{q}_{m}(t)+\frac{k_{f}+E_{f} I_{f}}{m_{f}}\left(\frac{m \pi}{l}\right)^{4} q_{m}(t)=\sum_{p=1}^{m_{0}} F_{s f p}(t) Y_{m}\left(x_{p}\right) \quad(m=1 \sim N M S S)
$$


where $E_{f} I_{f}, m_{f}$ stand for slab flexural rigidity and the linear mass density of concrete support layer. $k_{f}, c_{f}$ stand for the distribution stiffness and damping of subgrade along the length direction under the concrete support layer. NMSS is the modal order of the concrete support layer.

The dynamic equation of the coupled vehicle-track-subgrade coupling system can be obtained using eqns (1), (3), (13) and (14). With the Multi-step prediction-correction method based on Newmark, the equations of the coupled system dynamics can be solved. The step length is $\Delta t=0.0001 \mathrm{~s}$ in the process of solving.

\section{Calculation examples and result analysis}

\subsection{Calculation parameters}

According to Zhai [10], when the track length is more than $100 \mathrm{~m}$, calculation results are almost unaffected. Therefore, this paper selected $100 \mathrm{~m}$ as the length of the rail. The vehicle starts at the left-hand end of the track, and moving with the speed of $v=300 \mathrm{~km} / \mathrm{h}$ after the coupling vibration system transit to steady state within approximately $1 s$.

This paper adopted the CRH2 emu trailer; its parameters are listed in table 1, and the parameters of high-speed lines are listed in table 2.

Table 1: $\quad$ Parameters for a CRH2 emu trailer.

\begin{tabular}{|c|c|c|c|}
\hline Parameter & Value & Parameter & Value \\
\hline Mass of car body & $26100 \mathrm{~kg}$ & $\begin{array}{c}\text { Stiffness of primary } \\
\text { suspension }\end{array}$ & $1.176 \times 10^{6} \mathrm{~N} / \mathrm{m}$ \\
\hline Mass of bogie & $2600 \mathrm{~kg}$ & $\begin{array}{c}\text { Stiffness of secondary } \\
\text { suspension }\end{array}$ & $9.91 \times 10^{5} \mathrm{~N} / \mathrm{m}$ \\
\hline Mass of wheel set & $2100 \mathrm{~kg}$ & $\begin{array}{c}\text { Damping of primary } \\
\text { suspension }\end{array}$ & $1.02 \times 10^{6} \mathrm{~N} \cdot \mathrm{s} / \mathrm{m}$ \\
\hline $\begin{array}{c}\text { Pitch moment of } \\
\text { inertia of car }\end{array}$ & $1.28 \times 10^{6} \mathrm{~kg} \cdot \mathrm{m}^{2}$ & $\begin{array}{c}\text { Damping of secondary } \\
\text { suspension }\end{array}$ & $1.96 \times 10^{5} \mathrm{~N} \cdot \mathrm{s} / \mathrm{m}$ \\
\hline $\begin{array}{c}\text { Pitch moment of } \\
\text { inertia of bogie }\end{array}$ & $1424 \mathrm{~kg} \cdot \mathrm{m}^{2}$ & $\begin{array}{c}\text { Length between track } \\
\text { centres }\end{array}$ & $17.5 \mathrm{~m}$ \\
\hline Rigid wheelbase & $2.5 \mathrm{~m}$ & Radius of wheel & $0.43 \mathrm{~m}$ \\
\hline
\end{tabular}

According to the research results of Cai [12], the track irregularities of the Chinese new high speed line correspond with the Germanic low-disturbance line. Therefore, the Germanic low-disturbance spectrum was adopted as the track static irregularity in this paper. Fig. 3 shows the time domain random irregularity which was simulated by IFFT method based on the power spectral density (PSD) of the Germanic low-disturbance spectrum. 
Table 2: $\quad$ Parameters for high-speed lines.

\begin{tabular}{|c|c|c|c|}
\hline Parameter & Value & Parameter & Value \\
\hline Rail elastic modulus & $2.059 \times 10^{11} \mathrm{~N} / \mathrm{m}^{2}$ & $\begin{array}{l}\text { Distributed damping } \\
\text { of CA mortar }\end{array}$ & $3.458 \times 10^{4} \mathrm{~N} \cdot \mathrm{s} / \mathrm{m}^{2}$ \\
\hline $\begin{array}{c}\text { Rail rotational } \\
\text { inertia }\end{array}$ & $3.217 \times 10^{-5} \mathrm{~m}^{4}$ & $\begin{array}{c}\text { Elastic modulus of } \\
\text { track plate }\end{array}$ & $3.65 \times 10^{10} \mathrm{~N} / \mathrm{m}^{2}$ \\
\hline Mass of rail & $60.64 \mathrm{~kg} / \mathrm{m}$ & $\begin{array}{c}\text { Flexural rigidity of } \\
\text { track plate }\end{array}$ & $4 \times 10^{7} N \cdot s^{2}$ \\
\hline Stiffness of rail pad & $6 \times 10^{7} \mathrm{~N} / \mathrm{m}$ & $\begin{array}{l}\text { Elastic modulus of } \\
\text { support layer }\end{array}$ & $2.7 \times 10^{10} \mathrm{~N} / \mathrm{m}^{2}$ \\
\hline Damping of rail pad & $7.5 \times 10^{4} \mathrm{~N} \cdot \mathrm{s} / \mathrm{m}$ & $\begin{array}{c}\text { Flexural rigidity of } \\
\text { support layer }\end{array}$ & $4 \times 10^{7} N \cdot s^{2}$ \\
\hline $\begin{array}{l}\text { Length between } \\
\text { fasteners }\end{array}$ & $0.65 m$ & Mass of support layer & $602 \mathrm{~kg} / \mathrm{m}$ \\
\hline Length of slab & $6.45 m$ & Stiffness of subgrade & $1.25 \times 10^{9} \mathrm{~N} / \mathrm{m}^{3}$ \\
\hline Mass of slab & $8.6 \times 10^{3} \mathrm{~kg}$ & Damping of subgrade & $1.0 \times 10^{5} \mathrm{~N} \cdot \mathrm{s} / \mathrm{m}^{2}$ \\
\hline $\begin{array}{l}\text { Distributed stiffness } \\
\text { of CA mortar }\end{array}$ & $1.25 \times 10^{9} \mathrm{~N} / \mathrm{m}^{3}$ & & \\
\hline
\end{tabular}

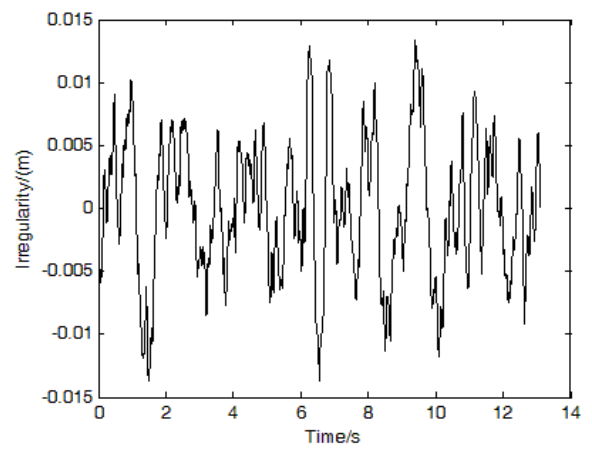

Figure 3: Time domain random irregularity sample of the Germanic lowdisturbance spectrum.

\subsection{Model validation}

In order to verify the proposed model, the comparisons with traditional dynamic model (Zhai-Sun's model) are given in fig. 4. The CA mortar is normal in this contrast experiment. In the traditional model of the track plate, CA mortar is simplified as spring and damping continuously distributed along track plate. The expression of motion equation described by the generalized modal displacement is:

$$
\ddot{T}_{n}(t)+\frac{c_{s} L_{s}}{M_{s}} \dot{T}_{n}(t)+\frac{k_{s}+E_{s} I_{s} \beta_{n}^{4}}{M_{s}} \cdot L_{s} \cdot T_{n}(t)=\sum_{j=1}^{n_{0}} \frac{F_{r s j}(t)}{M_{s}} X_{n}\left(x_{j}\right)
$$


In fig. 4, the vibration responses time histories of vehicle and track for these two methods, respectively, using traditional model of the track plate and the proposed model are shown. Fig. 4 shows that the results of two methods are close and the vibration amplitude of the proposed method is greater. To investigate the difference of the two methods, the normalized standard deviations of the vibration responses are listed in table 3 .

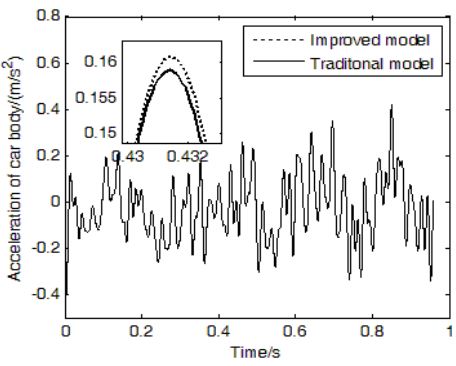

(a)

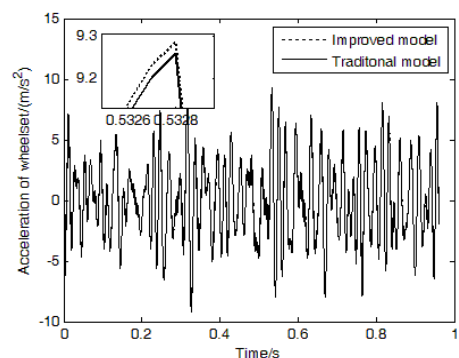

(c)

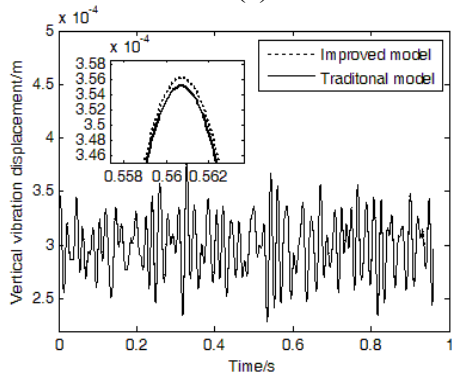

(e)

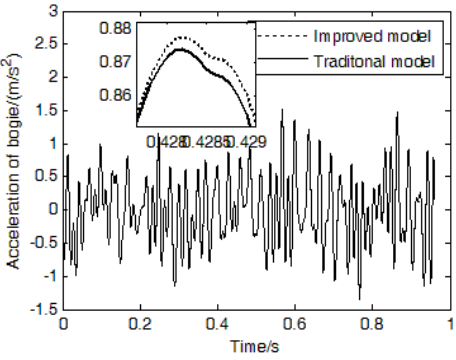

(b)

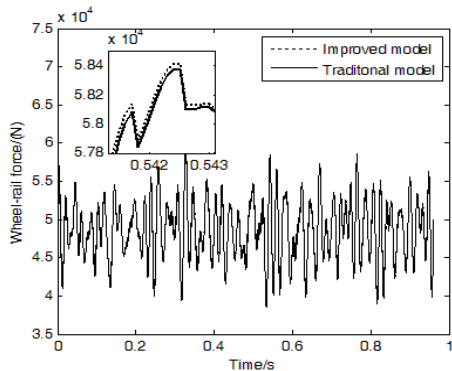

(d)

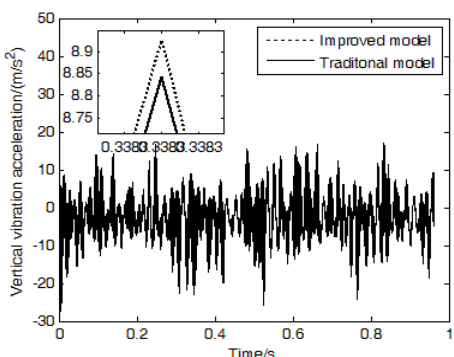

(f)

Figure 4: The comparison of vibration response of the proposed model with the traditional model; (a) acceleration of the car body; (b) acceleration of the bogie; (c) acceleration of the wheelset; (d) wheel-rail force; (e) displacement of the rail; (f) acceleration of the rail; (g) displacement of the track plate; (h) acceleration of the track plate. 


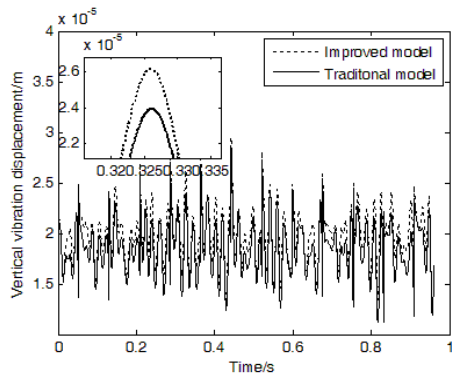

(g)

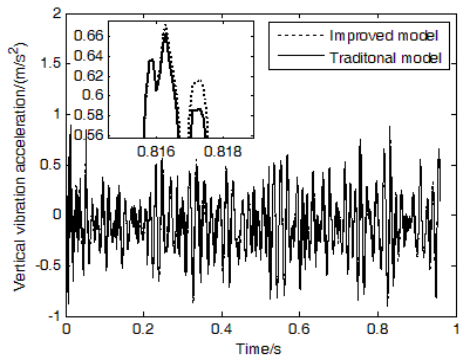

(h)

Figure 4: Continued.

From table 3, it can be seen that the normalized standard deviations of vibration responses are less than 0.01 except the displacement and acceleration of the track plate which manifests that the proposed method has basically concurred with the classical method. In addition, this paper adopted the vehicletrack-subgrade there-layer coupling model which is more than a layer than the traditional model. Therefore, it is effectively equivalent to decreasing the track generalized stiffness, and the vibration amplitude of the coupling system would increase. This is why the difference of track plate is much greater. Because of the primary, secondary suspension of the vehicle and the rail pad, the vehicle and rail is almost unaffected. According the above analysis, the proposed model is effective for simulating the vehicle-track dynamic with CA mortar deterioration.

Table 3: The normalized standard deviation of vibration responses of the two methods.

\begin{tabular}{|c|c|c|c|}
\hline Vibration responses & $\begin{array}{c}\text { Normalized } \\
\text { standard } \\
\text { deviation }\end{array}$ & Vibration responses & $\begin{array}{c}\text { Normalized } \\
\text { standard } \\
\text { deviation }\end{array}$ \\
\hline Acceleration of car body & 0.0066 & Displacement of rail & 0.0064 \\
\hline Acceleration of bogie & 0.0034 & Acceleration of rail & 0.0017 \\
\hline Acceleration of wheelset & 0.0024 & Displacement of track plate & 0.0436 \\
\hline Wheel-rail force & 0.0024 & Acceleration of track plate & 0.0255 \\
\hline
\end{tabular}

\subsection{Effect of CA mortar deterioration on the dynamic properties of a ballastless slab track}

Using the proposed model, the dynamic responses of track system with CA mortar deterioration were analyzed. The place of deterioration was set in the middle of the model under the track plate with the length of $1.95 \mathrm{~m}$. The effect of deterioration of CA mortar on track vibration response is shown in fig. 5.

Fig. 5 shows the contrast curves of vertical displacement and acceleration of the rail and track plate with no deterioration and when deterioration length is $1.95 \mathrm{~m}$. The vertical displacement of rail and track plate, the vertical vibration 
acceleration of rail and track plate will increase if the deterioration of CA mortar exists. The peak values of track plate in the deterioration area were analyzed quantitatively. The vertical acceleration of track plate rises from $0.5 \mathrm{~m} / \mathrm{s}^{2}$ to $1 \mathrm{~m} / \mathrm{s}^{2}$, about 2 times higher. The vertical displacement of track plate rises from $0.028 \mathrm{~mm}$ to $0.045 \mathrm{~mm}$, about 1.6 times higher. From fig. 5, we can see that the rail displacement and acceleration amplitude in the deterioration section of CA mortar is larger than normal line. The instantaneous impact of vehicle to rail is buffered by the stiffness and damping of rail pad. Therefore, the changes in rail are not bigger than track plate. According to the above analysis, the deterioration of CA mortar obviously enhanced the vibration phenomenon of track structure, which should be strictly controlled during the slab track maintenance.

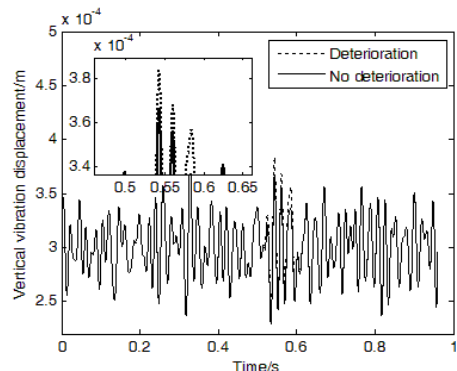

(a)

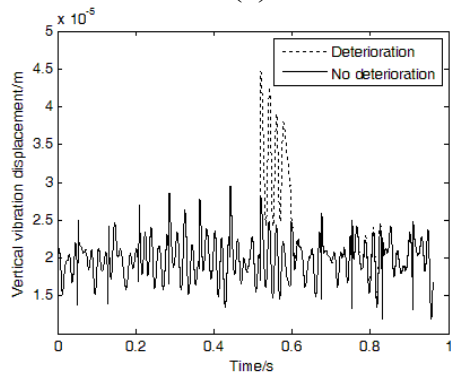

(c)

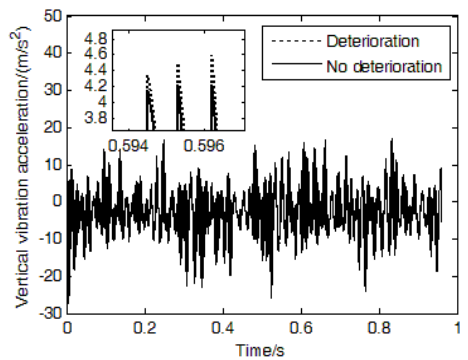

(b)

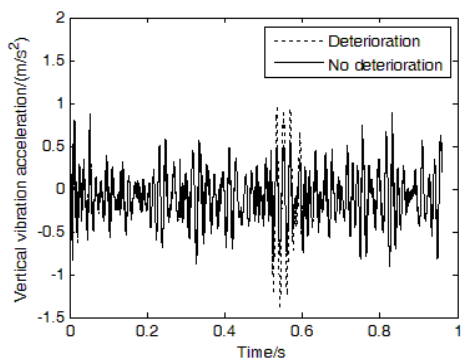

(d)

Figure 5: The effect of deterioration of CA mortar on track vibration response: (a) displacement of the rail; (b) acceleration of the rail; (c) displacement of the track plate; (d) acceleration of the track plate.

\section{Conclusions}

An improved method was proposed to establish a vehicle-ballastless tracksubgrade coupled system vertical improved model based on Matlab in this paper. CA mortar was discretized to many units. Each unit was simplified as spring and a damping concentrated on one point. This paper compared the proposed model with the traditional Zhai-Sun's model and analyzed the effect of deterioration of 
CA mortar on dynamic properties of a ballastless slab track. The following conclusions can be drawn.

(1) According to discretization of the CA mortar, the improved model can simulate the influences of CA mortar deterioration with an arbitrary length on the dynamic characteristics of a track. The proposed method has basically concurred with the classical method, and it is effective for simulating the vehicle-track dynamic with complicated track conditions.

(2) The vertical displacement of rail and track plate, the vertical vibration acceleration of rail and track plate will increase if the deterioration of CA mortar exists. The deterioration of $\mathrm{CA}$ mortar obviously enhanced the vibration phenomenon of track structure, which should be strictly controlled during the slab track maintenance.

The analyses of influences of CA mortar deterioration on dynamic properties of ballastless track have great application potentiality for further detection of CA mortar deterioration.

\section{Acknowledgement}

This research was supported by the National Science Foundation of China (61134003).

\section{References}

[1] Lu ZW, Railway Track of Passenger Dedicated Line, China Railway Publishing House: Beijing, pp. 47-50, 2005.

[2] Auersch L, Dynamics of the railway track and the underlying soil: the boundary-element solution, theoretical results and their experimental verification. Vehicle System Dynamics, 43, pp. 671-95, 2005.

[3] Bezin Y, Farrington D, Penny C, Temple B, Iwnicki S, The dynamic response of slab track constructions and their benefit with respect to conventional ballasted track. Vehicle System Dynamics, 48(1), pp. 175-93, 2010.

[4] Zhai WM, Han WJ, Cai CB, Dynamic Properties of High-speed Railway Slab Tracks. Journal of the China Railway Society, 21(6), pp. 65-69, 1999.

[5] Cai CB, Xu P, Dynamic analysis for frame slab track of high-speed railway. Journal of Vibration Engineering, 24(2), pp. 164-169, 2011.

[6] Guo YS, Yu ZJ, Shi HM, Effects of rail thermal stress on the dynamic response of vehicle and track. Vehicle System Dynamics, 53(1), pp. 30-50, 2015.

[7] Xiang J, He D, Zeng QY, Effect of cement asphalt mortar disease on dynamic performance of slab track. Journal of Central South University, 40(3), pp. 791-796, 2009.

[8] Wang L, Wang P, Wu RY, Common Deterioration Phenomena and Effect Analysis of Mortar Bed on CRTS- Track Structure. Railway Standard Design, (11), pp. 11-14, 2012. 
[9] Zhu H, Xu H, Xie KZ, Influence on CRTS- Slab Track Caused by the De-bonding of Emulsified Cement Asphalt Mortar. Railway Standard Design, (12), pp. 35-39, 2013.

[10] Zhai WM, Vehicle-Track Coupled Dynamics, third ed., Beijing Science Press: Beijing, pp. 20-40, 2007.

[11] Jia QF, Liu XJ, Mechanical and Structural Vibration, Tianjin University Press: Tianjin, 2007.

[12] Cai CB, Theory and Application of Train-Track-Bridge Coupling Vibration in High-speed Railways. Southwest Jiaotong University Doctor Degree Dissertation, Chengdu, 2004. 